\title{
Keeping the Song Alive in Mechanical Music Collections of New York and New Jersey
}

\author{
Jeremy Witten \\ Department of Music, University of Alberta, Edmonton, Alberta \\ Corresponding author: witten@ualberta.ca
}

\section{ABSTRACT}

Music boxes, musical clocks, nickelodeons and similar objects are commonly referred to as mechanical music or musical automata. New York and New Jersey have rich histories of manufacturing and archiving these objects. Often enclosed in display cases, curatorial attention has not always been paid to the music historically central to these objects. Therefore, this study examined how museums connect the materiality of these objects with their associated music. By synthesizing perspectives from museum studies, music history, and the history of design, five collections of musical automata in New York and New Jersey were examined: The Buffalo History Museum, The Herschell Carrousel Factory Museum, Thomas Edison National Historical Park, The Guinness Collection at the Morris Museum and the Cooper Hewitt Museum. Specifically, this project explored how musical automata produced between 1770 and 1930 have been archived, displayed and interpreted. By interviewing curators and analyzing museum collections, it ultimately appears that the curatorial strategies for mechanical music objects in New York and New Jersey are greatly varied. Additionally, a correlation was found between the proportion of a museum's collection dedicated to mechanical music and how interactive it is for the public.

\section{Introduction}

Music boxes, musical clocks, nickelodeons and similar objects are commonly referred to as mechanical music or musical automata. New York and New Jersey have rich histories of manufacturing and archiving these objects. Often enclosed in display cases, curatorial attention has not always been paid to the music historically central to these objects. Therefore, this study examined how museums connect the materiality of these objects with their associated music. By synthesizing perspectives from museum studies, music history, and the history of design, five collections of musical automata in New York and New Jersey were examined: The Buffalo History Museum, The Herschell Carrousel Factory Museum, Thomas Edison National Historical Park, The Guinness Collection at the Morris Museum and the Cooper Hewitt Museum. Specifically, this project explored how musical automata produced between 1770 and 1930 have been archived, 
displayed and interpreted. By interviewing curators and analyzing museum collections, it ultimately appears that the curatorial strategies for mechanical music objects in New York and New Jersey are greatly varied. Additionally, a correlation was found between the proportion of a museum's collection dedicated to mechanical music and how interactive it is for the public.

Much of the literature on mechanical music is limited to trade publications and collectors' repair manuals. For example, throughout this study, I encountered a multitude of historic band organ trade catalogs from companies like Artizan and the North Tonawanda Musical Instrument Works, as well as lengthy repair manuals such as Arthur Ord-Hume's Collecting Musical Boxes and How to Repair Them. In the world of academia, however, the subject of mechanical music has not been frequently discussed, despite the fact that it has connections to a multitude of scholarly disciplines including museum studies, the history of design, and music history. This study makes evident the many interdisciplinary applications of mechanical music; the objects themselves are multimodal and easily lend themselves to interdisciplinary interpretation. A musical jewelry box, for instance, is multipurpose, not created solely for listening to its contained song. The physical reality of these objects could benefit from perspectives in design history, while the sonic reality of these objects would benefit from perspectives in music history. Once these objects are displayed in museums, they gain an additional conceptual layer that could be addressed well in museum studies.

\section{Definition of Mechanical Music}

Although the term mechanical music is commonly associated with music boxes, the Music Box Society International (MBSI) provides a more comprehensive definition of mechanical music, which includes everything "from a music box to a fairground organ or anything in between, such as a musical clock, singing bird box, band organ, reproducing piano, orchestrion, nickelodeon, musical snuff box, automaton or automatic musical instruments of any kind" (Little). The MBSI's decision to include the Edison Phonograph Museum, the Johnson Victrola Museum, and Edison National Historic Park in its list of mechanical music museums shows that the phonograph has a noteworthy place in the history of mechanical music. Following the MBSI, this paper employs a broad definition of mechanical music that includes phonographs. Nevertheless, there is an important difference between a cranked music box and a cranked phonograph. Although both are cranked, the melody contained on the disc or cylinder of a music box is not a recorded performance. Conversely, the crank on the phonograph allows the transmission of a recorded performance by powering the phonograph to play the record. While a phonograph allows you to play different records, the musical component of a music box is typically hidden inside the box and there is no opportunity to play anything other than the music initially contained on the disc or cylinder. The decision to use a broad definition of mechanical music stems from the fact that although these objects may differ mechanically, they pose the same curatorial problems to a museum. Indeed, they are all fragile mechanical objects of sound from 1770 to 1930, and a curator must decide whether it is possible to honour the musicality of the object while simultaneously considering its fragility.

\section{Historical Background}

In the 1967 publication Collecting Music Boxes and How to Repair Them, Arthur Ord-Hume historically situates some of the earliest music boxes in the late 1700s:

The evolution of the small musical movement was made possible by the invention, in 1796, of the tuned steel comb by one Antoine Favre of Geneva. Before this, any attempt to produce a tune mechanically, other than with an organ machine, had been severely hampered as regards compactness because it had to comprise a carillon of bells struck by hammers (Ord-Hume, 11) 
Although the tuned steel comb was invented in 1796 , the height of mechanical music's popularity began in the 1820s. Michele Marinelli, Curator of the Guinness Collection at the Morris Museum in Morristown, New Jersey, explained this history as it pertains to the Guinness Collection at the Morris Museum:

Most of the instruments [of the Guinness Collection] are from the 19th century... The earliest piece we have is from about 1600 and that's a bear-it's a clock. But the bear is an automaton; he's animated [but not musical]... It was in the late 1700s that the musical mechanism was first developed... Music boxes typically came out of Switzerland, disc players typically came out of Germany and for automata the center of the industry was Paris (Marinelli).

In addition to Michele Marinelli's focus on the European history of mechanical music, the Herschell Carrousel Factory Museum lists the "European origins of carrousels, band organs and amusement rides" as one of its "priorities for research" ("Mission Statement"). It is interesting to note, however, that the history of mechanical music is not limited to European contexts. In the year 1206, the Syrian author Al-Razz Al Jazari's wrote Al-Jmi bain al-IIm wal-amal al-Nmi sinat al-hiyad (The Book of Knowledge of Ingenious Mechanical Devices), and in 1796, Kazuo Murakami published Karakuri Zui, which was translated to English and published under the title Japanese Automata in 2012. Although the popularity of mechanical music in nineteenth century America may have been influenced by mechanical music from Switzerland, Germany and France, such publications show that mechanical music has a geographical history that is broader than the continent of Europe. I am indebted to Arthur OrdHume for providing this broader geographical context for the history of mechanical music.
In the context of the United States in the late eighteenth and early nineteenth century, however, mechanical music objects were initially imported from Europe. Soon afterward, these objects came to be manufactured in North America as a response to rising importation fees. After visiting New York City and seeing a carrousel in Central Park, Scottish industrialist Allan Herschell was inspired to start his own carrousel company in North Tonawanda. Herschell was a key figure in the development of mechanical music in North America and is the man for whom the Herschell Carrousel Factory Museum (HCFM) is named. In a personal interview, HCFM Organ Specialist and Board Trustee Douglas Hershberger explained that "mechanical music in the U.S.A. started in North Tonawanda, and almost all the merry-go-round organs built in the U.S. came from five factories within walking distance of [the Herschell Carrousel Factory Museum]." Hershberger went on to outline more of the relevant mechanical music history in North Tonawanda:

Herschell didn't just build carrousels-that started in 1883, about nine years after they came to America and opened their foundry. 1872 is Herschell; in 1883 Herschell builds his first merry-go-round. In 1893 they've set up Eugene de Kleist to build band organs. So between 1883 and 1893, when they sold a carrousel, the customer had to get his own band organ from an importer in New York... So de Kleist was the first manufacturer in the United States, but there were importers (Hershberger, Personal interview).

It is beyond the scope of this paper to tell the full history of the production of band organs in North Tonawanda in the late nineteenth and early twentieth century. What is important to note from Hershberger, however, is that the first Americanmade band organs were built in 1893 in western New York. Band organs, sometimes referred to as fairground organs, are so named because they were intended to mechanically imitate the sound of a full 
band. Around the same time that Herschell and de Kleist were manufacturing band organs in western New York, New Jerseyan cities were flourishing with mechanical music manufacturing. Guinness Collection curator Michele Marinelli explained some of the relevant mechanical music history in New Jersey:

New Jersey was a hub in the country for producing music. Many [European] companies were right here in our own state. In Germany, Polyphon and Symphonium were the top two companies and there were also Swiss companies like Mermod, but the reason why they began to be produced here [in New Jersey] is because the U.S. was increasing their importation fees and it was becoming too expensive to import so they started a branch here in New Jersey. Polyphon/Symphonium was right in Bradley Beach/Asbury Park... The Regina Music Box Company was in Jersey City and then they moved to Rahway because they expanded tremendously. The Aeolian Company was right in Garwood, New Jersey and F.G. Otto was in Jersey City (Marinelli).

The important mechanical music manufacturing work that was taking place in New York and New Jersey is clear. In 1887 , at the same time that the Aeolian Company began manufacturing player pianos in New York City, Thomas Edison began making phonographs in West Orange, New Jersey. In 1892, the Regina Music Company was founded in New Jersey, and in 1893, as has been mentioned above, Allan Herschell brought Eugene de Kleist from Germany to North Tonawanda to manufacture band organs. While this historically situates mechanical music manufacturing in the United States, it does not speak to the museums of New York and New Jersey that began collecting and archiving these objects in the twentieth century. Despite the fact that the history of music boxes dates back to the 1770s in Switzerland, it does not appear that music boxes were collected by museums in New York and New Jersey until the 1930s, though private collections existed earlier than this. Cooper Hewitt: The Smithsonian Design Museum acquired its first music box in 1938, with further music box acquisitions made in the 1940s and 1950s. Within that time period, the Music Box Society International formed, having its first meeting in 1950. In 1973 the National Carrousel Association formed, and in 1997, the Coin Operated Collectors Association was founded. After the death of mechanical music collector Murtogh D. Guinness in 2002, the Morris Museum of Morristown, New Jersey acquired his collection of mechanical music.

The 150-year time span between the earliest European music boxes and the earliest acquisitions of these objects by American museums is intriguing. The distinction between mechanical music and recorded sound may help explain why mechanical music was not seen in museum collections in New York and New Jersey until the 1930s. A nineteenth century phonograph and a nineteenth century music box pose similar curatorial problems to a curator interested in making both objects sonically interactive. But while these objects can be grouped together in a twenty-first century curatorial context, it is important to distinguish them when discussing the history of mechanical music. Music boxes, player pianos and organettes saw a decrease in popularity in the twentieth century, and the decision made by museums to begin collecting these objects may be tied to the work of Thomas Edison. In many ways, Thomas Edison's invention of the phonograph in 1877 signaled a shift away from the aforementioned music mechanisms and a move toward recorded sound. Music boxes, player pianos, and organettes seem like old technology when compared with playable sound recordings. Perhaps the reason one does not see mechanical music in museum collections until the 1930s is that the phonograph served to obsolesce music boxes, player pianos, and organettes, thereby making the latter objects seem antiquated and worthy of preservation in museums. 
Despite these key historical differences between the phonograph and other musical mechanisms of the nineteenth century, there are important connections between a phonograph and a player piano, for example. A piano roll can be made by documenting the notes struck by a player during a live performance. The pianist strikes the keys and the perforator responds by punching holes into the roll paper. Here the line between mechanical music and recorded sound is blurred. Both a phonograph record and a piano roll can be thought of as "recordings" in the broadest sense. To summarize, while discussing the acquisition of mechanical music objects by museums, there are three important points to consider: (1) a diverse range of mechanical music objects pose the same curatorial problems to museums, (2) the historical significance of the phonograph distinguishes it from other mechanical music objects, and (3) despite the historical distinction between the phonograph and other music mechanisms, it is difficult to draw a firm line between mechanical music and recorded sound.

Now that mechanical music has been defined and its history considered as it pertains to New York and New Jersey, the above can be considered in relation to the operational research question: With respect to five mechanical music collections in New York and New Jersey, how have curators archived and displayed mechanical music objects produced between 1770 and 1930? In order to address this question, it is necessary to give an overview of the five mechanical music collections. The five collections are shown in the chart below.

Table 1. Mechanical music collections at five museums in New York and New Jersey

\begin{tabular}{|c|c|c|c|c|c|}
\hline & $\begin{array}{l}\text { Cooper } \\
\text { Hewitt }\end{array}$ & $\begin{array}{l}\text { Buffalo } \\
\text { History }\end{array}$ & Edison & Guinness & Herschell \\
\hline Music box & 4 & 4 & & 311 & \\
\hline Musical clock & 1 & & & 6 & \\
\hline Barrel organ & & & & 6 & 1 \\
\hline Carrousel & & & & & 2 \\
\hline Player organ & & 1 & 1 & 5 & \\
\hline Player piano & & 1 & & 6 & 1 \\
\hline Singing bird box & & 1 & & 11 & \\
\hline Street organ & & 1 & & 2 & \\
\hline Organette & & 5 & & 7 & \\
\hline Band organ & & & & 2 & 4 \\
\hline Automaton & 3 & & 3 & 235 & \\
\hline Other musical novelty & & & & 164 & \\
\hline Phonograph & & & 252 & 5 & \\
\hline Piano/organ roll & & 400 & 72 & 5000 & 200 \\
\hline Total (excluding rolls) & 8 & 13 & 256 & 760 & 8 \\
\hline
\end{tabular}




\section{Methodology}

There were three methods involved in the data collection. First, I completed background research on mechanical music exhibiting practices. Second, I created comparative analyses of the five collections, based on criteria documented in the literature review and from subsequent on-site observations. Third, I interviewed curators in New York and New Jersey. These methods addressed my research question in the following ways: (1) the literature review provided historical basis for mechanical music objects, and a vocabulary with which to approach them, (2) visiting museums and analyzing displays allowed me to apply the vocabulary acquired in the literature review, and (3) interviewing curators in New York and New Jersey allowed me to document a range of curatorial strategies, objectives and perspectives relating to musical automata from 1770-1930.

\section{Results}

The total mechanical music objects at each museum (Table 1) is somewhat misleading. At first it may appear that Edison National Historic Park has a greater focus on mechanical music than the Herschell Carrousel Factory Museum. The total, however, does nothing to show a museum's relative focus on mechanical music within their entire collection. The size of a museum's collection is constantly changing, so it is difficult to come up with a precise percentage to represent a museum's focus on mechanical music. Instead, when analyzing each museum's relative focus on mechanical music, my research was qualitative in nature, based on things such as whether or not each museum had a specific section for mechanical music, and whether they had specialists or dedicated staff for their mechanical music collections. My ranking of the museums from those that are least focused on mechanical music to those that are most focused on mechanical music is as follows: (1) Cooper Hewitt, (2) The Buffalo History Museum, (3) Edison National Park, (4) The Guinness Collection at the Morris Museum, and (5) The Herschell Carrousel
Factory Museum. Here Cooper Hewitt has the smallest focus on mechanical music whereas the collections at Herschell Carrousel Factory Museum and the Guinness Collection at the Morris Museum were primarily dedicated to mechanical music objects. Because the interactivity of mechanical music collections was focal to this research, the fact that this order essentially corresponds to level of interactivity within each collection is noteworthy. Here, interactivity was understood as allowing a museum patron to either touch the object or engage with its musicality in some way. Essentially there was a correlation between (1) a museum's relative focus on mechanical music within its larger collection and (2) how interactive that collection has been made for the public; the greater the focus on mechanical music, the more interactive the collection.

I also noticed a correlation between the age of a museum and the interactivity of its mechanical music collection. The Herschell Carrousel Factory Museum opened in 1983 and the Guinness Collection at the Morris Museum opened two decades later in 2003. These museums are newer and their policies are more open to interactivity. Conversely, the museums that are less interactive opened before 1960. Cooper Hewitt was founded in 1896, and began acquiring mechanical music objects in 1938, while the Buffalo History Museum opened in 1901. Thomas Edison's home was designated a National Historic Site in 1955, and the United States National Park Service began overseeing the site in 1962.

\section{Discussion}

At Cooper Hewitt, the collection of mechanical musical instruments is small (eight in total) and Cooper Hewitt's exhibition documentation shows that only one music box has ever been displayed publicly ("Music Box and Key, Late 19th Century"). Other than the one music box, which was displayed from November 2016 to May 2017, the other seven objects have been kept in an offsite storage facility in Newark, New Jersey and can only be viewed 
by researchers. Despite the fact that Cooper Hewitt's collection of mechanical music is not sonically interactive, Cooper Hewitt has made their entire physical collection interactive in a multitude of other ways. The Cooper Hewitt Pen, for example, allows museum patrons to scan museum object codes as they tour the museum, creating a digital record of each object they scan. In this way, Cooper Hewitt is a leader with museum technology and interactivity, despite the fact that this has not yet extended to the music contained in its mechanical music objects. Because of this, Cooper Hewitt is listed as the least interactive mechanical music collection of the five museums included in this study. This seems understandable considering the small focus on mechanical music in the context of their entire collection.

The Buffalo History Museum also has a very small amount of its collection dedicated to mechanical music. In terms of interactivity, The Buffalo History Museum offers more opportunities for interactivity than Cooper Hewitt. The Buffalo History Museum allows occasional public demonstrations of its player pipe organ but it does not have a mechanical music expert on staff. Appendix A features an interview with Walter Mayer, the museum's Director of Collections. As is shown in the interview, public demonstrations are dependent upon an outside expert expressing interest in the object and receiving permission from the Director of Collections. The lower level of the Buffalo History Museum contains an area called The Street of Shops with some mechanical music objects on display. The Street of Shops is a lifesize reconstruction of a commercial street in Buffalo in the 1870s. Museum visitors can walk down this reconstructed street and look in the windows of a variety of historic Buffalo businesses. One shop, called the Adam, Meldrum \& Company Store, features a hand-cranked roller organ, as well as two organettes. These instruments are behind glass and therefore physically inaccessible. Walter Mayer articulated his own observation that museum attendees have shown increasing interest in the music contained in the mechanical objects:

Down in The Street of Shops, at one time people would have been satisfied with just seeing it. Now that's gone; they want to hear it. I think that's where technology can come in, where you could record it and provide the interactive: you push a button and you hear the music... So, we're thinking of getting a couple people that belong to that mechanical instrument society and bringing one of them in to record it... within the next couple years (Mayer).

As Walter Mayer explains, the Buffalo History Museum is exploring possibilities for making audio recordings of its mechanical musical instruments, in addition to their openness to public demonstrations of the player pipe organ.

In terms of interactivity, Edison National Historic Park offers more opportunities than the previous two museums. The park's Sound Curator Jerry Fabris explained the following about the museum's different collections:

There's the Museum Collection and there's also the Archives... but then a third much smaller category of the collection is what we call the Teaching Collection. With the Museum Collection and the Archives, the idea there is to preserve the collection, to just make sure it's always protected, safe, doesn't get damaged... Now the Teaching Collection is a little different. It's a much smaller collection, but the idea of the Teaching Collection is that we choose or find artifacts that are not particularly rare, do not have any direct hands-on association with Edison or the laboratory, but allow us to actually use the collections... The phonographs that you'll see in Building Five of the laboratory, we don't use those phonographs because we keep them intact because 
they have a direct association with the laboratory (Fabris).

The Teaching Collection was created in 1993 when the museum wanted to have a collection with increased interactivity for educational programs. Not only does Edison Park's collection reflect a larger focus on mechanical music, they have developed a special collection for interactive use, which is something neither Cooper Hewitt nor The Buffalo History Museum have done with their collections of mechanical music.

The Guinness Collection at the Morris Museum and the Herschell Carrousel Factory Museum both are museums with the majority of their collections dedicated to mechanical music. The Guinness Collection was analyzed as a museum itself, since it has its own staff and distinct location within the Morris Museum. Despite the different curatorial strategies employed at The Guinness Collection at the Morris Museum and the Herschell Carrousel Factory Museum, they are both highly interactive. Michele Marinelli, Curator of the Guinness Collection, participated in an interview about the level of interactivity within the Guinness Collection, which is excerpted in Appendix B. The Guinness Collection at the Morris Museum has taken at least three different approaches to making their collection interactive. First, they offer scheduled daily demonstrations of mechanical music. Second, they have an accessibility program that allows a specific demographic (visually-impaired museum visitors) to physically touch the objects. Third, the museum has made digital recordings of their mechanical music recordings, some of which are triggered through cranks that mimic components of mechanical music objects.

Lastly, the interactivity of the collection at the Herschell Carrousel Factory Museum was emphasized in interviews with Director Rae Proefrock and Organ Specialist Douglas Herhsberger. After I mentioned that some museums keep mechanical music objects in storage or in display cases, Director Rae Proefrock offered a different curatorial approach:

We have an entirely different philosophy. To us, most of our artifacts, the carrousels, the rides outside, the band organs, they were made to be used, they need to be ridden or heard, so how can you possibly appreciate the full experience of that object just by looking at it? You just can't do it. So, our board made a decision, very early on, that these were going to be operated, the rides would be ridden because that's how you appreciated the work of the artisans who made them. They could not be appreciated just by viewing them. We've had to make that argument quite strongly for some of our grant applications because it's not normal in a museum to use the objects (Proefrock).

Additionally, Hershberger has stated, "[we] believe that a merry-go-round ride without a real band organ playing is only half a ride, so we play our organs every day" (Herhsberger, "A Letter from..."). The Herschell Carrousel Factory Museum has a barrel reed organ that they allow museum visitors to operate during tours. This differs from the Morris Museum because the museum staff and guides will operate the instruments of the Guinness Collection as opposed to the museum visitors. The curatorial mandate at the Herschell Carrousel Factory Museum is primarily rooted in appreciation and the joy associated with mechanical music. Hershberger articulated this sentiment in the interview when he stated:

The slogan of the Carrousel Organ Association of America is: "The Happiest Music on Earth!" And in a lot of ways, that's true. I can't explain it in musical terms-why it is that. But it is definitely energetic, lighthearted, usually popular music, although there's opera rolls, there's sacred rolls, there's ethnic rolls, there's blues rolls. Every kind of music there is, you can get in a mechanical music machine. Now 
we're basically talking about carrousel organs, which is just one little corner of mechanical music... But it's inimitable. Those machines make that noise. And everyone recognizes it (Herhsberger, Personal interview).

The philosophy and curatorial approach at the Herschell Carrousel Factory Museum was different than the other museums, and each museum staff member had an energetic appreciation for mechanical music. Additionally, museum visitors constantly hear mechanically produced songs while walking through the buildings and the grounds.

\section{Conclusion}

Many museums display mechanical music objects in ways that reduce interactivity and mask the musicality of the objects. In doing so, curators have prioritized physical preservation over musical transmission. These curatorial practices serve to silence the songs that were historically central to the objects. A museum's relative focus on mechanical music appears to have a positive correlation with that mechanical music collection's level of interactivity for the public. However, there is still public demand to hear mechanical music objects even in museums with a relatively small focus on mechanical music. For example, mechanical music makes up only a small component of the collection at the Buffalo History Museum, yet Director of Collections Walter Mayer has still noted the desire of museum attendees to hear the music of these objects. Museums that have taken time to make their mechanical music collections accessible speak extensively of the public appreciation of such curatorial decisions. When taken in consideration with the many possibilities that contemporary digital technology provides for preserving mechanical music, the results of this study show that museums with a small focus on mechanical music should not ignore the curatorial successes achieved by museums like The Herschell Carrousel Factory Museum and the Guinness Collection at the Morris Museum.
For a part of the world that has such a rich history of manufacturing these diverse musical objects, it is valuable that several museums in New York and New Jersey are now archiving and displaying these objects. Museums that focus on mechanical music reflect a passion for the musicality of the objects in their mission statements. The value placed on the music of the objects is then reflected sonically through many diverse curatorial practices including public demonstrations, museum visitor operation of the instruments, digital recordings for museum visitors, accessibility programs for the blind, online video recordings of the objects and much else. Since music was initially central to these objects, it seems appropriate that several museum curators are exploring new ways to both preserve and continue to allow some form of access to the songs contained within these objects.

\section{Acknowledgements}

I would like to thank Dr. Joan Greer for her role as supervisor of this project and the Undergraduate Research Initiative for providing funding that supported this work. In addition, I would also like to extend my gratitude to all the curators and museum staff who were interviewed including Jerry Fabris, Doug Hershberger, Michele Marinelli, Walter Mayer, and Rae Proefrock. Special thanks to Knowles Little, Arthur Ord-Hume, Cynthia Trope, and Carl Urion for providing insight in email correspondences. Research ethics approval for this project was provided by The University of Alberta Research Ethics Office. 


\section{Appendix A: Interview with Walter Mayer of the Buffalo History Museum - July 8, 2016}

JW: How often is this player pipe organ demonstrated to people?

WM: On request and I'm always up-front with the people. The most recent time... A few years ago, there was a conference here in Buffalo of mechanical instruments and they had requested to have it played for them and we did. But at the same time, somebody, around this time last year (what would have been July 2015), somebody from Chicago wanted to hear it and what have you. I think they were somewhat disappointed but I try to tell them that there were a lot of dead notes to it. And like I said, we couldn't just turn it on and walk out of the room because the rolls they tend to-I don't know if it's at all part of this restoration problem-but the timing, the speed of the roller is now duller and slipping.

JW: Interesting. Typically, how much advance notice would the museum have to have in order to accommodate a request?

WM: You know, a couple of days. It would depend on my schedule.

JW: And you're the one who operates it?

WM: I try to stay away from it because I really don't feel competent in operating it.

JW: Is there a specialist?

WM: No there isn't on staff. So, what we'll do is, I'll want to know if they know how to operate it, if they have an expertise in it or something. But I wouldn't just let anyone come in off the street and say "Oh here, put the roll on"

JW: What about the street organ?

WM: That's never been played. At least, that I'm aware of.

JW: And do you recall if the music boxes or organettes have been on display recently or when they were last on display?

WM: No, they haven't been on display recently. 


\section{Appendix B: Interview with Michele Marinelli of the Morris Museum - July 22, 2016}

JW: It's interesting because at the Edison Collection, they have the real historical stuff that Edison used that they don't let anyone touch. But then in the '90s they started a new collection called The Teaching Collection and that's all the stuff that's related but not nearly as historically significant because, you know, it would be like a replica or something like that but they use it for the programming so that, you know, kids can actually turn it, you know, get a phonograph to play.

MM: Yeah, we don't have the staff or the funds to do something like that. Everything we have that we work with is what Mr. Guinness collected. Most of it is vintage-to be kind. There is an exception: we do have an accessibility program here, using-they're just food service disposable gloves. We have, particularly, when we have visually impaired people, we have certain objects that we will bring out-like everything you saw on the counter, those are not part of the Guinness Collection. They're real, they're authentic, they're old, but they just they're not part of the Guinness collection. So, we will bring those out and while they, you know, many of these people have-they have different levels of sight, of vision. Very few are $100 \%$ percent blind. But with this way we can allow them to feel these different parts as we describe them, we'll do visual description. What we do is like that disc player, for example, we'll describe it so that they can feel it. Of course, they hear it and then we have individual components-parts that Jerry has from the workshop-and they can feel them and then they can start putting it all together because they have the pieces as a whole piece. So that's one way of allowing people to touch. But unfortunately, that's just this particular the accessibility program, it's not for the general public.

JW: But you do have other stuff or you're planning on getting other stuff for allowing the general public to physically interact with the mechanical music? Because I noticed there are the ones that are recorded in the Guinness Collection, you turn a crank but you're not actually operating the machine. I'd never seen that before I thought it was really interesting kind of curatorial strategy.

MM: Unfortunately, that's not going to happen. The public are not going to be able to operate the machines.

JW: Whose idea was that to make a crank that you could turn that would control a digital recording?

MM: That was probably-I'm the third curator since the collection arrived here. We acquired the collection in 2003 and the first curator was here I think until maybe 2008/2009-maybe somewhere around there. And then we had a second curator. She was only here about a year and a half I think it most. And I've been the curator since. 


\section{References}

Al-Jazari, Abu I- Ezz, and Fuat Sezgin. Compendium on the Theory and Practice of the Mechanical Arts:Aljami' Bain Al-'ilm Wa-L-'amal An-Nafi' Fi Sina'at Al-Hiyal. Frankfurt am Main: Institute for the history of Arabic-Islamic Science, 2002. Print.

Fabris, Jerry. Personal interview. 22 July 2016.

"Music Box and Key, Late 19th Century." Ellen DeGeneres Selects. 11 Nov. 2016 - 21 May 2017. Cooper Hewitt: The Smithsonian Design Museum, New York City.

Hershberger, Douglas. "A Letter from the President of the Board." The Carrousel Courier, vol. 22, May 2016, p. 2. <www.carrouselmuseum.org/site/wp-content/uploads/2014/05/Newsletter-Spring2014right.pdf $>$.

Hershberger, Douglas. Personal interview. 8 July 2016.

Kazuo, Murakami. Japanese Automata, Karakuri Zui: An Eighteenth Century Japanese Manual of Automatic Mechanical Devices. Senda Yasuko Publishing, 2012.

Little, Knowles. "Home Page." The Music Box Society International. N.p., Web. 9 Sept. 2016. <http://mbsi. org>.

Ord-Hume, Arthur. Collecting Musical Boxes and How to Repair Them. 1 ed., New York, Crown Publishers Inc., 1967.

Marinelli, Michele. Personal interview. 22 July 2016.

Mayer, Walter. Personal interview. 8 July 2016.

"Mission Statement." Herschell Carrousel Factory Museum. N.p., 13 Aug. 2013. Web. 9 Sept. 2016. <http:// carrouselmuseum.org/site/about/mission-statement-2>.

Proefrock, Rae. Personal interview. 8 July 2016. 